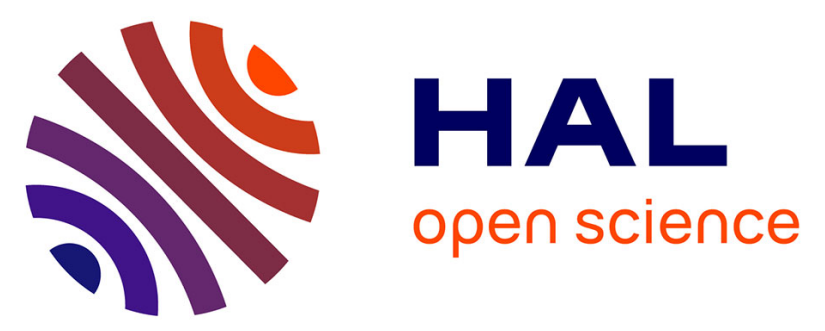

\title{
Applying Closed-Loop Product Lifecycle Management to Enable Fact Based Design of Boats
}

\author{
Moritz Von Stietencron, Karl A. Hribernik, Carl Christian Røstad, Bjørnar
} Henriksen, Klaus-Dieter Thoben

\section{- To cite this version:}

Moritz Von Stietencron, Karl A. Hribernik, Carl Christian Røstad, Bjørnar Henriksen, Klaus-Dieter Thoben. Applying Closed-Loop Product Lifecycle Management to Enable Fact Based Design of Boats. 14th IFIP International Conference on Product Lifecycle Management (PLM), Jul 2017, Seville, Spain. pp.522-531, 10.1007/978-3-319-72905-3_46. hal-01764183

\section{HAL Id: hal-01764183 \\ https://hal.inria.fr/hal-01764183}

Submitted on 11 Apr 2018

HAL is a multi-disciplinary open access archive for the deposit and dissemination of scientific research documents, whether they are published or not. The documents may come from teaching and research institutions in France or abroad, or from public or private research centers.
L'archive ouverte pluridisciplinaire HAL, est destinée au dépôt et à la diffusion de documents scientifiques de niveau recherche, publiés ou non, émanant des établissements d'enseignement et de recherche français ou étrangers, des laboratoires publics ou privés.

\section{(c)(1)}

Distributed under a Creative Commons Attribution| 4.0 International License 


\title{
Applying Closed-Loop Product Lifecycle Management to Enable Fact Based Design of Boats
}

\author{
Moritz von Stietencron ${ }^{1(\bowtie)}$, Karl A. Hribernik ${ }^{1}$, Carl Christian Røstad ${ }^{2}$, Bjørnar Hen- \\ riksen $^{2}$, Klaus-Dieter Thoben ${ }^{1,3}$ \\ ${ }^{1}$ BIBA - Bremer Institut für Produktion und Logistik GmbH at the University of Bremen, Bre- \\ men, Germany \\ sti@biba.uni-bremen. de \\ ${ }^{2}$ SINTEF Technology and Society, Trondheim, Norway \\ ${ }^{3}$ Faculty of Production Engineering, University of Bremen, Bremen, Germany
}

\begin{abstract}
In the design of both leisure as well as professional boats, the experience of the boat designers and builders traditionally play a central role. To reach the desired customer satisfaction especially with high powered vessels, which often are used for decades, the tendency of overengineering is imminent. This is mainly based on the lack of reliable testing data and the high costs of towing tank tests and complex hydro dynamic simulations. The paradigm of Closed-Loop Product Lifecycle Management (PLM) can be employed as the enabling technology to overcome this lack of objectiveness by supplying the necessary product usage information to improve these processes. This paper presents an explorative approach towards a fact-based design and development process utilising distributed sensor data acquisition and high performance computing to enhance and validate the hydrodynamic simulations during the development process with the objective to reduce costs and uncertainties while increasing development speed and customer satisfaction. Beyond the related work and detailed description of the solution approach, this paper explores a concrete application experiment and gives conclusions on the applicability of Closed-Loop PLM as well as the other employed technologies.
\end{abstract}

Keywords: High Performance Computing, Closed-Loop PLM, IoT, Product Development, Product Usage Information, Hydro Dynamic Simulations

\section{$1 \quad$ Introduction}

The trade of boat builders is a very traditional and cautious one, in which the personal knowledge of the craftsmen plays a central role. This imposes the industry with a number of limitations to both the productivity as well as the level of innovation that can be safely achieved from product generation to product generation.

While some categories of boat producers can adopt the processes from other mass production industries, this is not applicable for the manufacturers of specialised vessels, which need to find new and innovative approaches to combine expert knowledge with

adfa, p. 1, 2011.

(C) Springer-Verlag Berlin Heidelberg 2011 
intelligent decision support. The paradigm of closed-loop Product Lifecycle Management (PLM) postulates the shift from the traditional management of CAD-files towards a management of product information from all lifecycle phases.

This paper presents an approach to help specialised boat manufacturers to evolve their design and production processes based on real life product usage information.

\section{Background and Motivation}

Many producers of standardised, mass-produced boats have long abandoned the "craftsman"-approach to boat building and have heavily invested in a design driven process, which yields vessels, that fulfil the demands of a vast majority of common customers. However, the producers of small series vessels, and those with especially high demands to functional capabilities, are struggling to evolve their design and production processes as uncertainty and high investments currently do not calculate a promising business model. While the feedback from captains and boat-owners is usually anecdotal, without real data as the foundation for engineering decisions, many boats do have sensors, but, usually, the resulting data are neither collected nor transmitted to the boat manufacturer.

With the vision to improve the traditional process of designing small series of specialised boats and especially their hulls in a way, that eradicates the need for repetitive and costly rounds of prototype development, production and testing, we explored the possibilities to enhance the development process of boats for professional use by introducing real life product usage information and high performance computing (HPC) fuelled hydrodynamic simulations into the product design process.

In other domains different approaches towards product design and development processes which are not based merely on personal experience but also on actual product usage information - like fact-based design - have emerged over the recent years [1]. In fact-based design, in-situ information about product usage (usage information) is collected and consequently integrated into decision-making processes [2].

For the experiment a 6-step process for the usage of product usage information in vessel design was adapted, comprising the following steps:

1. Usage Data Collecting

2. Data Analysis

3. Design of Simulation Scenarios

4. Coupling of Data and Simulation

5. Running the Simulation

6. Creating a Better Boat

This paper will detail the related work and approach taken to address this idea and discuss the experiments results. 


\section{$3 \quad$ Related Work}

This section presents an overview of three main topics - Fact-based design for boats, Product Lifecycle Management, and Internet of Things - which form the basis of the research presented in the subsequent chapters.

\subsection{Fact-based design for boats}

In vessel design, the lack of data the customers' actual product usage patterns, results in a largely retrospective product-design based on experience, subjective judgments with external input only from certain customers or key persons. This often results in too high or wrong quality-standards and consequently over-processing. [1] However, a systematic product development approach needs to combine the knowledge from people that know the customers' demands and service requirements with that of the craftsmen producing the vessel. Product development research has explored several approaches, like concurrent engineering as a means to capture product usage information and mobilize them to enable reuse of the gained knowledge in the product development process [3]. Besides the trend towards a formalization of the product development process the capturing and utilization of product usage information is more and more seen as a competitive advantage in the domain. [4]

\subsection{Product Lifecycle Management}

Product Lifecycle Management (PLM) can be interpreted from the marketing as well as from the production engineering perspective. [5] The production engineering perspective on PLM has evolved from Product Data Management (PDM, also known as technical data management / TDM or engineering data management / EDM) [6]. It often divides the product's lifecycle into three main phases: beginning-of-life (BOL), middleof-life (MOL) and end-of-life (EOL). [7] The BOL comprises steps such as product development, production and distribution and as primary focus of traditional PDM still is the "heart" of the conventional PLM.

With the emergence of paradigms like extended products, product service systems, functional products and the like, the need for a more extensive management of the product's lifecycle has been fostered. Thus, the latter phases of the product's lifecycle have gained more recognition in PLM. The MOL represents the use phase and the EOL the reverse logistics. [8] Fig. 1 shows the three phases of a "closed-loop" product lifecycle with main processes. 


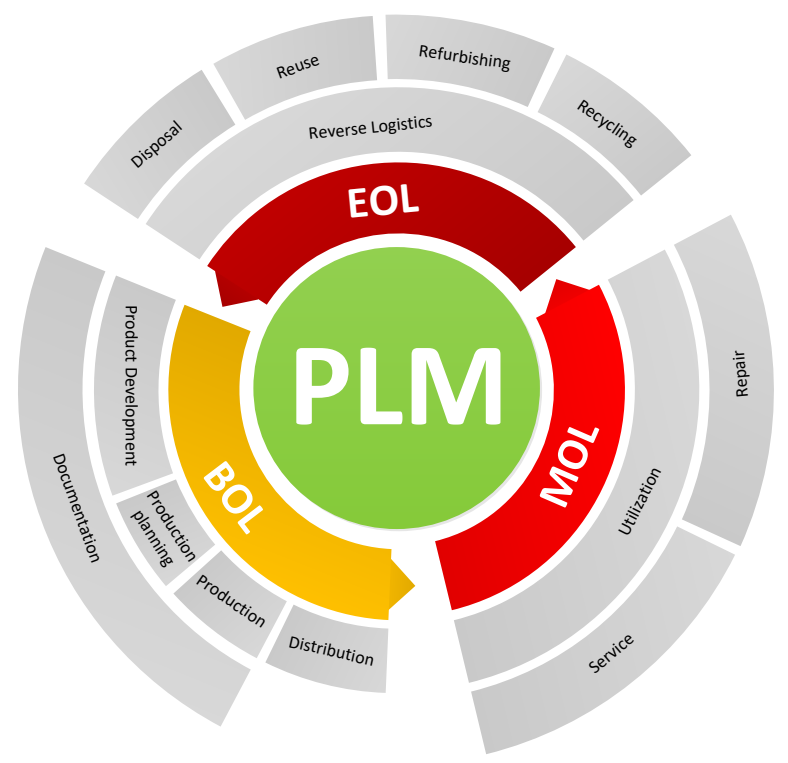

Fig. 1. PLM Phases and Processes; adapted from $[9,10]$

The paradigm of closed-loop PLM describes an ecosystem in which stakeholders of a product can control product information originating from any phase in the product's lifecycle and utilize them throughout all lifecycle phases. [11] In this view it is crucial to combine information flows of as many product phases as possible - or ideally all. [12]

While BOL and EOL regularly are of little direct interest to the customer or end user, the MOL features direct interaction with the user. [10] While direct user interaction enables the straightforward creation of new business models, it also imposes a barrier between product and producer in the MOL phase, hindering direct access to product information from this phase. This is even increased in control and security sensitive industries like the maritime sector.

Therefore, the integration of the MOL phase as the regularly longest phase, requires, that technologies which enable product - producer interaction without customer involvement, like the Internet of Things (IoT) need to be employed.

\subsection{Internet of Things}

The product services of the 21st century are broadly supported by and reliant on the internet [13]. This trend is further increased by the possibilities of the Internet of Things (IoT). The Internet of Things can be seen as an evolution of the "old" human driven internet towards an internet which is driven by inanimate objects - things [14]. Originating in the wake of radio frequency identification (RFID) technology the IoT encompasses every object that participates in data exchange with other systems. It does not make any difference whether this exchange is multilateral or not, neither what sort of system is observed. [15] 
While of course the recent technological developments have made the IoT the international trend it has become, by its underlying definition some of the simpler systems (like RFID), which qualify as IoT components, have been around for decades and are already respectively wide spread in the industry without having their full potential exploited. Now, that this exploitation is becoming more and more feasible for many use cases this existing, and sometimes almost forgotten, data wealth can be accessed.

\section{$4 \quad$ Methodology}

This section will present the approach and prototypical implementation chosen in the experiment.

\subsection{Approach}

Based on the overall process as described in section 2 we identified the following tasks to be handled by the experiment, that are beyond the capabilities of the boat manufacturer and their engineering associates:

1. Capture and Handling of Product Usage Data

2. Management and Visualization of Data

3. Coupling of Data to Simulations

The design of the simulation and coupling of data to the simulation were executed by the simulation experts of the boat manufacturer and external subcontractors which are already involved in the boat design process.

\subsection{Use Case}

Hydrolift is a renowned Norwegian boat manufacturer that recently developed a new rescue vessel - the Hydrolift P42 - designed for high speed operations based on a modular design with focus on a high level of safety, functionality and cost of ownership.

In addition of being an innovative, efficient and a fast running vessel this new class also has great towing capacity and the possibility of carrying a watercraft. State of the art navigation equipment VHF, double chart plotters, radar and thermal imaging camera is also included. Our experiment has been carried out in parallel to the prototype testing and finalisation process.

\subsection{Experiment}

To achieve the first two objectives of the experiment, we implemented an IoT system for the collection, management and visualization of sensor data from the prototype vessels as a flexible system which was designed for ease of use and maximum flexibility on utilization. It is comprised of a data acquisition unit installed on the prototype boat (named the Universal Marine Gateway) and a cloud based data management and visualization application (named the HighSea Designer). 
Capture and Handling of Product Usage Data. The data acquisition unit "Universal Marine Gateway" (UMG) is a modular data acquisition unit for product centric sensor data, which has been especially adapted to the marine domain. It was employed to collect sensor data from the boat's on-board systems which are connected via a NMEA2000 bus as well as dedicated sensors that have been strategically placed on the vessel.

The UMG has been implemented within the experiment in multiple versions depending on the vessel prototype status. Fig. 2 shows the UMG as implemented on the final vessel prototype.

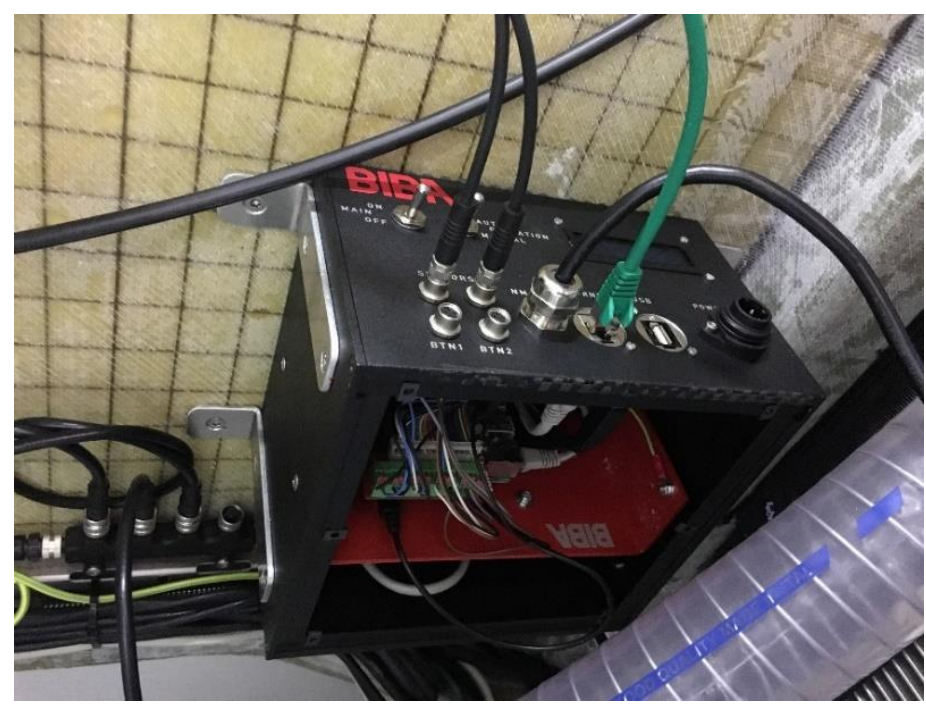

Fig. 2. The Universal Marine Gateway as implemented on final Hydrolift P-42 prototype

From the NMEA2000 bus the existing on-board systems can be accessed, which delivers access to an already vast number of vessel related data sources like fluid levels, engine and drivetrain status as well as weather, position, speed and more.

Beyond the pre-existing, yet not readily available, data set of the on-board systems, the simulation and product development experts have identified the need for advanced acceleration and orientation data from the vessel. To cater to this need two Bosch BNO055 ${ }^{1}$ system in package inertial measurement units have been installed, one at the hull's center of gravity (see Fig. 3, left) and one attached to the heavily dampened captain's chair (see Fig. 3, right).

1 https://www.bosch-sensortec.com/bst/products/all_products/bno055 


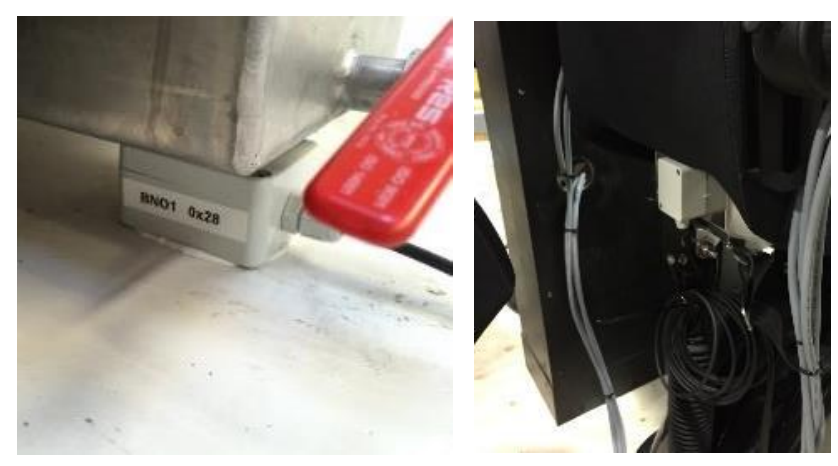

Fig. 3. Bosch BNO055 IMU sensor installations on Hydrolift P-42

Management and Visualization of Data. The cloud based HighSea Designer is a IoT platform which receives the sensor data from the UMG and manages them. Beyond the data management, it offers online data analysis and showcasing of different test runs for preselection before handing them over to the use in the further design processes.

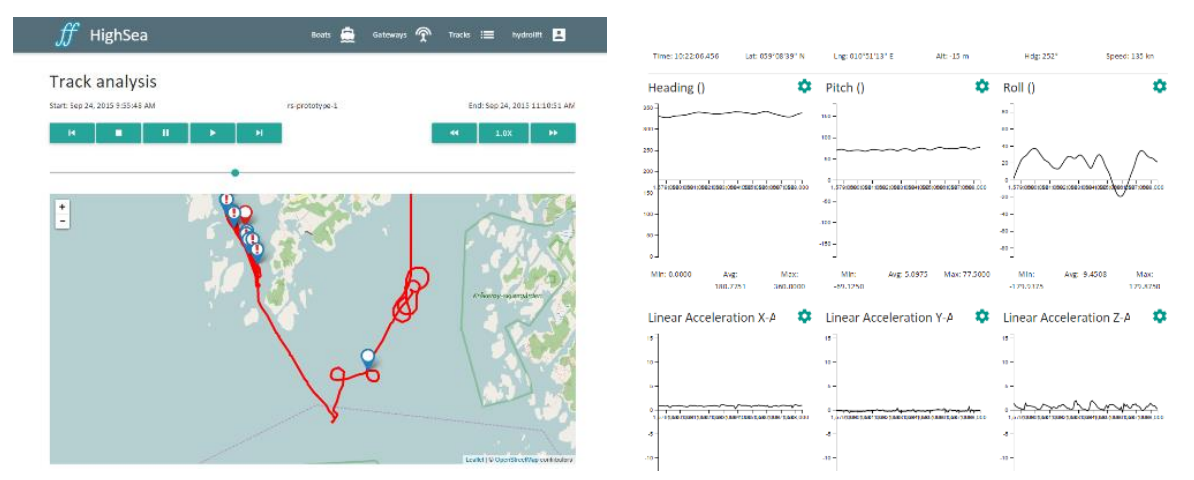

Fig. 4. Screenshot of Hydrolift P-42 test run analysis in the HighSea Designer

Fig. 4 gives examples of the graphical user interface which presents the data from a specific prototype test run.

Coupling of Data to Simulations. While the first two objectives could be addressed from a technical direction the coupling of the sensor data from the test runs to the improved simulations was more a methodic task. It was decided in the experiment to pursue a two-fold approach:

1. Using preprocessed sensor data as input to the simulation scenario,

2. Comparing real-life sensor data to simulated data points observing the same object. 
For both approaches the accelerations measured on the hull and the captain's chair were used as reference data and coupled with an adapted simulation model of the P-42. The simulations were run on the CINECA High Performance Computing Centre.

\section{$5 \quad$ Results}

The evaluation period of the experiment has enabled us to collect sensor data from over 100 test runs of the Hydrolift P-42 prototype.

Since the boat prototype has passed through different stages, with different technical system on-board, the data acquisition tool chain has encountered minor issues with short-term changes in configurations.

Based on the amount of sensor data it became apparent that in wide spread applications automated selection of relevant test runs would be advisable to enable easy selection of valid sensor data. The prototypical cloud application developed proved useful to conduct selection and validation of a smaller batch of test runs based on both the geo-profile of the test run as well as the sensor readings.

The data coupled simulations were dubbed in the experiment as "virtual sea trials". During the experimentation, it proved more achievable to utilize the real-life sensor data to verify the validity of the simulation results. And initiate an iterative process of simulation improvement, thus enabling the simulations to reach the necessary credibility.

From the concept of the virtual sea trials, validating the simulations based on reallife prototype run data, it is anticipated that the vessel design process can be significantly streamlined.

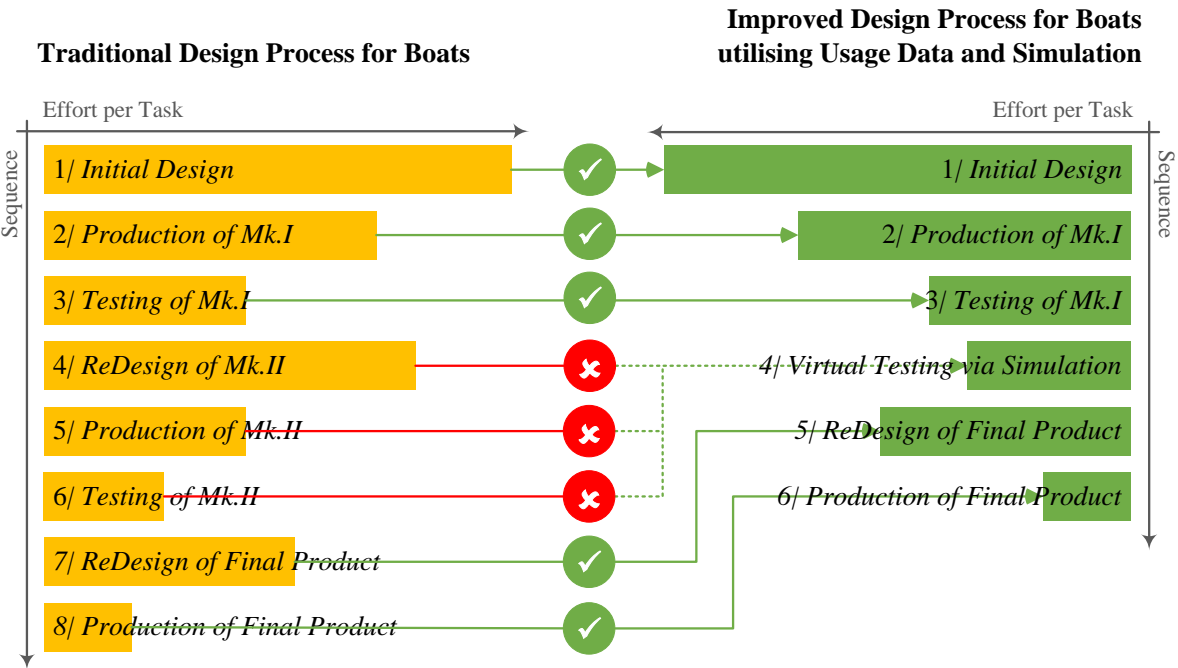

Fig. 5. Traditional (left) and Improved (right) Design Processes for Boats

Fig. 5. shows the impact of replacing repetitive prototype development, production and testing with a virtual sea trial. It is estimated that employing this approach can lead 
to savings of up to $15 \%$ on the prototype analysis and simulation efforts across the whole value chain.

\section{Conclusions}

The research presented in this paper has explored a possibility of introducing fact-based design processes into the development of boats. A combination of real-life usage data captured from on-board systems as well as dedicated sensors and hydrodynamic simulations run in high performance computing centres has been chosen. The system implemented has successfully shown the potential of capturing sensor data from real-life test runs and transferring them back to the design process for use in or validation of simulations thus reducing uncertainties and development costs significantly.

Based on the successful experimentation in this experiment follow up developments have been initiated by the partners. Most notably the consortium has jointly engaged in the EC-funded project LINCOLN - Lean Innovative Connected Vessels ${ }^{2}$ to expand both the development of the Internet of Things approach to vessel data capturing and usage as well as the employment of high performance computing and simulations for vessel design. However, the demonstrated approach not only holds potential for the boat developers' design and development processes; it also paves the way for new value adding business models which can be based on the now available usage data.

Acknowledgements. The research leading to these results has received funding from the European Community's seventh framework programme (FP7) under grant agreement No 609029 as well as the European Union's Horizon 2020 research and innovation programme under grant agreement No 727982.

The contents of this paper reflect only the authors' view and the Commission is not responsible for any use that may be made of the information it contains.

The authors would like to thank the other projects partners - especially Hydrolift AS - for the support and openness in the creation of this paper.

\section{References}

1. Røstad CC, Henriksen B (2012) ECO-boat MOL capturing data from real use of the product. In: IFIP International Conference on Product Lifecycle Management. Springer, pp 99110

2. Wellsandt S, von Stietencron M, Hribernik K, Henriksen B, Røstad CC, Thoben K-D (2015) Fact-based Design for Leisure Boats: The HighSea-experiment Setup. Procedia CIRP 38:74-77.

3. Jo HH, Parsaei HR, Sullivan WG (1993) Principles of concurrent engineering. In: Concurrent engineering. Springer, pp 3-23

4. Henriksen B, Røstad CC, Naume C (2016) Modularization Fact-Based Design to Increase "the Room to Maneuver." 6th International Conference on Information Systems, Logistics and Supply Chain ILS Conference 2016, June 1 - 4, Bordeaux, France (in Press)

2 http://www.lincolnproject.eu 
5. Sundin E (2009) Life-cycle perspectives of product/service-systems: in design theory. In: Introduction to product/service-system design. Springer, pp 31-49

6. Terzi S, Bouras A, Dutta D, Garetti M, Kiritsis D (2010) Product lifecycle managementfrom its history to its new role. International Journal of Product Lifecycle Management 4:360-389.

7. Kiritsis D, Bufardi A, Xirouchakis P (2003) Research issues on product lifecycle management and information tracking using smart embedded systems. Advanced Engineering Informatics 17:189-202.

8. von Stietencron M, Hribernik KA, Røstad CC, Henriksen B, Thoben K-D (2016) An IoT fueled DSS for MOL Marine Auxiliaries Management. Product Lifecycle Management for Digital Transformation of Industries. doi: 10.1007/978-3-319-54660-5

9. Hans C, Hribernik KA, Thoben KD (2010) Improving reverse logistics processes using item-level product life cycle management. International Journal of Product Lifecycle Management 4:338-359.

10. Hribernik KA, von Stietencron M, Hans C, Thoben K-D (2011) Intelligent Products to Support Closed-Loop Reverse Logistics. Glocalized Solutions for Sustainability in Manufacturing 486-491.

11. Kiritsis D (2011) Closed-loop PLM for intelligent products in the era of the Internet of things. Computer-Aided Design 43:479-501.

12. Jun HB, Kiritsis D, Xirouchakis P (2007) Research issues on closed-loop PLM. Computers in industry $58: 855-868$.

13. Thoben K-D, Wortmann JC (Hans) (2012) The Role of IT for Extended Products' Evolution into Product Service Ecosystems. In: Emmanouilidis C, Taisch M, Kiritsis D (eds) Advances in Production Management Systems. Competitive Manufacturing for Innovative Products and Services. Springer Berlin Heidelberg, pp 399-406

14. Ashton K (2009) That "internet of things" thing. RFiD Journal 22:97-114.

15. Atzori L, Iera A, Morabito G (2010) The internet of things: A survey. Computer networks 54:2787-2805 